\title{
Империализм как последняя стадия
}

В.и. КЛИстоРИн, доктор экономических наук, Институт экономики и организации промышленного производства СО РАН, Новосибирск. E-mail: klistorin@ieie.nsc.ru

Статья посвящена анализу известной брошюры В.И. Ленина «Империализм, как высшая стадия капитализма», столетие со дня завершения работы над которой исполняется в этом году. Рассмотрены с сегодняшних позиций экономические и политические тенденции, которые В.И. Ленин анализировал сто лет назад, и выводы, к которым он пришел. Также рассмотрены некоторые работы тех лет, на которые опирался и которые критиковал В.И. Ленин в этом тексте. Кратко изложены теории монополии, монополистической конкуренции и финансового капитала. В СССР из брошюры В.И. Ленина была создана целая наука «Политическая экономия государственно-монополистического капитализма». Сделана попытка выявить влияние этой науки на развитие научной мысли и практической политики в СССР и России.

Ключевые слова: империализм, монополии, банки, биржи, конкуренция, финансовый капитал, олигархия, раздел мира, войны

Весной-летом 1916 г. В.И. Ленин закончил работу над своей знаменитой брошюрой «Империализм, как высшая стадия капитализма» [1. С. 299-426], которая спустя год была напечатана в Петрограде в издательстве «Жизнь и знание». Вне зависимости от содержания эта работа сыграла огромную роль в жизни нашей страны, да и не только. Сам В.И. Ленин определил свое произведение как «популярный очерк». Но в СССР из этого очерка выросла целая наука - политическая экономия государственномонополистического капитализма [2-4] ${ }^{1}$.

Подтолкнула В.И. Ленина к написанию этой работы переписка с Н.И. Бухариным, который в 1915 г. опубликовал статью «Мировое хозяйство и империализм» [5. С. 21-93], послужившую предметом обсуждения.

В предисловии к своей книге В.И. Ленин выделяет работу Джона А. Гобсона «Империализм», на которую часто ссылается на протяжении всего текста. Кроме того, он цитирует и обсуждает

\footnotetext{
${ }^{1}$ Работыпрофессора НГУ С.М. Меньшикова ипрофессора университета Пизы, члена ЦК Компартии Италии А. Пезенти указаны специально для того, чтобы показать, что знание зарубежной научной литературы и экономической жизни не избавляет людей от идеологической предвзятости, чем бы она ни была вызвана.
} 
работы множества других авторов, среди которых следует выделить социалистов Рудольфа Гильфердинга и Карла Каутского. Примечательно, что к буржуазным авторам В.И. Ленин относится с большим уважением, а к их выводам - с бо́льшим доверием, чем к социалистическим писателям. Видимо, это объясняется не только более высоким качеством и степенью научности исследований буржуазных авторов, но и тем, что В.И. Ленин и его единомышленники рассматривали социалистов как политических конкурентов, в отличие от либералов и консерваторов, которые были просто классовыми врагами. В предисловии к французскому и немецкому изданиям в 1920 г. В.И. Ленин писал: «Особенное внимание уделено в настоящей книжке критике “каутскианства”, международного идейного течения, которое представлено во всех странах мира “виднейшими теоретиками”, вождями II Интернационала» [1. С. 306].

В.И. Ленин представил очень жесткую и цельную структуру и внутреннюю логику своей работы, которая проста для изучения и изобилует формулами, легкими для запоминания. Надо отметить, что в конце XIX - начале XX века в интеллектуальной среде был очень популярен так называемый «экономизм», или материалистический подход к истории, т. е. представление о том, что все социальные и политические процессы и события можно объяснить, исходя из экономических, которые, в свою очередь, подчиняются неким объективным законам.

Разделяя позицию Г.В. Плеханова в монистическом взгляде на историю, В.И. Ленин вывел чеканную формулу: политика есть концентрированное выражение экономики. Позитивизм в духе Г. Спенсера и О. Конта тогда критиковался последовательными марксистами, которыми считали себя большевики, поскольку они отвергали саму идею внеклассовой науки, лишенной идеологических и ценностных оценок. Справедливости ради отметим, что тогда позитивизм был неприемлем и для ученых многих других направлений, которые пытались найти причины территориальной экспансии европейских держав, конфликтов и войн, миграции населения и капитала и многого другого в объективных процессах развития производительных сил, обусловленных объективными же экономическими законами.

В тезисном виде «Империализм» В.И. Ленина выглядит следующим образом. 
Положительный эффект масштабов ведет к концентрации производства и капиталов. Это приводит к образованию монополий в промышленной и банковской сферах. Слияние банковского и промышленного капитала образует финансовый капитал и порождает финансовую олигархию, которая, в свою очередь, экспортирует капитал в колонии и зависимые страны, что и делает необходимым раздел мира между ведущими странами для защиты инвестиций. Завершение раздела мира и неравномерность экономического развития стран приводят к войнам за передел мира. Монополии господствуют внутри отдельных стран и на международной арене, что способствует усилению паразитизма буржуа, превращению метрополий в государства-рантье, объединению и социализации производства и распределения в мировом масштабе. Благодаря сверхприбылям монополии становятся паразитами и ведут к загниванию экономики и общества. Таким образом, империализм есть высшая и последняя стадия капитализма. Созданы все материальные и организационные предпосылки для мировой революции. Империализм есть канун социальной революции пролетариата [1. С. 308].

\section{Теории монополии}

Монополии и выгоды, проистекающие из монопольного положения на рынке, известны с древнейших времен. А. Смит связывал возникновение монополий с государством, которое устанавливает привилегии для отдельных субъектов. Для него было очевидно, что экономический прогресс состоял в переходе от государственно-монополистического капитализма к капитализму свободной конкуренции.

К. Маркс и его последователи разделяли идею стадий социально-экономического развития общества, каждая из которых развивалась и гибла, подчиняясь собственным законам. Поэтому, с их точки зрения, капитализм начинался с переходом к свободному рынку. Оставалось непонятным, каким образом новая формация вызревала в недрах старой, почему институты капитализма могли возникнуть и в достаточной степени оформиться в феодальном обществе. Это противоречило основной идее формационной теории, в которой материальные производительные силы были активным фактором, а институциональная надстройка была консервативной и служила интересам господствующих классов. 
Во второй половине XIX века был замечен феномен монополий иного типа - возникающих практически без участия государства. Разумеется, коррупция и другие неформальные отношения между бизнесом и государством играли значительную роль в формировании монополий, но главными причинами их появления были технический прогресс и образование новых отраслей промышленности, развитие транспорта.

Монополии вызывали недовольство значительной части общества, и первые антитрестовские законы были приняты еще в конце XIX века (закон Шермана 1890 г.), но это не слишком помешало их развитию. При этом само государство способствовало росту монополий путем предоставления концессий, распределения государственных заказов, развития патентного права и т. д.

Хотя А. Курно построил первую модель монополии еще в 1838 г., работы по этой проблеме долгое время носили в основном описательный характер, а теории монополии являются достижением XX века.

Дж. Б. Кларк резко отрицательно относился к монополиям, считая их средством грабежа и тормозом технического прогресса. Но он показал, что в случае растущей предельной производительности капитала (как, например, в транспортной инфраструктуре) монополии неизбежны, и они должны регулироваться государством. Примечательно, что к монополиям он относил и профсоюзы.

П. Сраффа в своих работах начала 1920-х годов показал, что наличие множества производителей не делает рынок совершенно конкурентным. Его следует рассматривать как множество локальных монопольных рынков, когда каждый предприниматель формирует свой собственный рынок. Э. Чемберлин в 1933 г. опубликовал замечательную работу «Теория монополистической конкуренции» [6]. В предисловии к русскому изданию этой книги Ю. Я. Ольсевич писал: «Для него (Чемберлина) монополистическая конкуренция не некое нарушение нормального состояния, ведущее к потере равновесия в хозяйственной системе, а напротив, одна из характеристик нормального равновесного состояния рынка. Причем состояния, исключающего эксплуатацию наемного труда и соответствующего потребностям покупателей. Чемберлин выступает лишь против одного типа монополий - профсоюзов» [6. C. 6-7].

В 1934 г. Г. фон Штакельберг опубликовал работу «Структура рынка и равновесие», в которой показал, что асимметрия 
информации приводит к асимметрии выигрышей в случае олигополии. Рассмотрение монопольной прибыли как квазиренты привело к разработке множества теорий олигополии. Обзор теорий монополии начала - середины XX века приведен в работе А. Пезенти [4. С. 138-176].

Й. Шумпетер доказывал, что в основе монополии лежат инновации, следовательно, она не может быть вечной, а антимонопольная политика, скорее всего, будет контрпродуктивна, поскольку сдерживает «созидательное разрушение» и не позволяет раскрыться потенциалу инноваций. Ф. фон Хайек придерживался сходной точки зрения, поскольку считал, что монополии транслируют верную информацию о своей сверхприбыльности. Это привлекает на рынок конкурентов и способствует структурным сдвигам в экономике и, в конечном счете, к разрушению монополии.

В современном понимании монополия связывается с наличием барьеров, как правило, институционального характера, асимметрией информации и инновациями. Монополия является научной абстракцией, а рынки скорее олигополистические. Поэтому прогнозы К. Каутского и многих других о том, что на смену капитализму свободной конкуренции идет организованный, отрицающий конкуренцию, пока не оправдались. Вообще линейная экстраполяция на длительные периоды обычно бывает ошибочна.

\section{Финансовый капитал}

Понятие финансового капитала ввел Р. Гильфердинг в своей одноименной работе [7]. Это произведение представляет интерес не только для историка науки, но и с точки зрения экономической истории вообще. Разумеется, его теория денег во многом устарела, поскольку денежные системы разных стран изменились до неузнаваемости. Но Р. Гильфердинг одним из первых заметил, как финансовые инновации влияют на возможность аккумуляции финансовых ресурсов и перераспределение прибыли, описал механизмы трансформации сбережений в инвестиции и т. п.

Его вывод о том, что «курсовая стоимость акционерного капитала всегда выше, чем стоимость капитала, функционирующего в нормальных условиях» [7. С. 159], и вытекающая из него теория фиктивного капитала в настоящее время получили совсем другую интерпретацию. Описание функционирования фондовой и товарной бирж для того времени вполне корректно, но упреки 
в том, что биржевые цены никак не связаны с издержками и потому подрывают условия воспроизводства в отдельных секторах и странах, явно необоснованны [7. С. 215].

Следуя марксистской традиции, Р. Гильфердинг считал, что «прибыль возникает в производстве и реализуется в обращении» [2. Т. 1. С. 231]. Но поскольку обращение также требует использования капитала, прибыль в торговле, финансах, банковской деятельности и т. д. «есть вычет из прибавочной стоимости, так как они имеют дело лишь с реализованными стоимостями (даже если происходит только в виде долговых требований)» [7. С. 232]. В связи с тем, что капитал в основном концентрируется в посреднической сфере, производственный капитал все более подчиняется капиталу, занятому в сфере обращения, что и является основой для образования финансового капитала.

Даже сейчас интересно читать рассуждения Р. Гильфердинга о влиянии финансового капитала на различные стороны экономической жизни: воспроизводственный процесс, миграцию капиталов, открытие новых рынков, последствия протекционистской политики, захват колоний, влияние на циклическое развитие экономики и многое другое. Его выводы не всегда согласуются с нашими представлениями, но заставляют задуматься об изменениях, происшедших в экономике за последние сто лет.

Как и многие другие писатели, Р. Гильфердинг связывает господство финансового капитала и финансовой олигархии с идеологией империализма и достаточно подробно обсуждает формирование идеологии империализма вместе с пересмотром самой концепции государства. «Финансовому капиталу необходимо было государство достаточно сильное, для того чтобы проводить политику экспансии и присоединять новые колонии. Либерализм был противником государственной политики силы, он хотел обезопасить свое господство от старых сил аристократии и бюрократии, предоставляя им средства государственной власти в минимальном объеме» [7. С. 433]. Именно с господством финансового капитала Р. Гильфердинг связывает усиление расистских и ксенофобских настроений. «Возникает идеология империализма, идущая на смену идеалам старого либерализма. Она высмеивает наивность последнего... Достигнуто подчинение интересов индивидуума высшим общим интересам. Чуждое народу государство и сама нация связаны в единое целое, 
и национальная идея в качестве движущей силы сделалась служанкой политики» [7. С. 434-435].

Завершает свою работу Р. Гильфердинг почти как В.И. Ленин, провозглашая финансовый капитал высшей ступенью полноты экономической и политической власти, сосредоточенной в руках финансовой олигархии, и тезисом о неизбежности превращения диктатуры магнатов капитала в диктатуру пролетариата. Что действительно отличает марксизм - так это признание тесной связи между экономическими, социальными и политическими процессами, которой сторонники неоклассического направления уделяли недостаточно внимания.

В конце жизни Р. Гильфердинг пересмотрел свое отношение к марксизму, но в 1910 г. он еще не отошел от него. В предисловии к обсуждаемой работе он писал: «Марксизм часто упрекали за то, что он пренебрегал дальнейшим развитием экономической теории, и упрек этот, до известной степени, не лишен объективных оснований» [7. С. 43] и прилагал значительные усилия для развития марксистской концепции и объяснения в ее рамках новейших тенденций в эволюции рыночной экономики.

\section{Империализм сто лет спустя}

Анализ новейших тенденций в развитии капитализма, проведенный В.И. Лениным, был во многом верен хотя бы потому, что основывался на критическом рассмотрении множества работ предшественников. Обсуждаемая работа В.И. Ленина представляет собой высококачественный реферат и критический обзор научной литературы тех лет. Оригинальность ее состоит в выводах, которые В.И. Ленин сделал на основании этого обзора. И не все из них прошли проверку временем.

Прежде всего, это касается утверждения о монополистическом капитализме как о высшей и последней стадии капитализма и неизбежности социалистической революции в мировом масштабе. Как известно, в том же 1916 г. В.И. Ленин говорил о том, что революция в России - дело отдаленного будущего, но она неизбежна. Революции действительно произошли в ряде стран, но принесли ли они освобождение рабочего класса и невиданный расцвет производительных сил - большой вопрос.

Гораздо ближе к реальному развитию ситуации оказались институционалисты, прежде всего Дж. А. Гобсон, полагавший, что 
развитие демократических институтов и парламентаризма может обуздать всевластие монополий и империалистические захваты. Не сразу, но постепенно в общественном мнении возобладала мысль, высказанная еще Дизраэли, что колонии - жернова на ногах империи. Двадцатый век показал, что территориальные захваты и милитаризация экономики, необходимая для внешней экспансии и удержания присоединенных территорий и странклиентов, обходятся чрезвычайно дорого.

Ряд тенденций, описанных В.И. Лениным, не имели продолжения или были преувеличены. Так, следуя К. Марксу, В.И. Ленин считал, что «банки создают в общественном масштабе форму, но именно только форму, общего счетоводства и общего распределения средств производства» и далее пишет об «общем счетоводстве» всего класса капиталистов и даже не только капиталистов» [1. С. 332].

Не подтвердилась гипотеза о том, что банки вытеснят биржу. Ссылаясь на работу Шульце-Геверница, В.И. Ленин писал, что «смена старого капитализма, с господством свободной конкуренции, новым капитализмом, с господством монополии, выражается, между прочим, в падении значения биржи. «Если таким образом суживается область действия автоматически функционирующих экономических законов и чрезвычайно расширяется область сознательного регулирования через банки, то в связи с этим гигантски возрастает и народнохозяйственная ответственность немногих руководящих лиц» [1. С. 334]. Близкие идеи мы встречаем у Р. Гильфердинга: «Монополистические союзы совершенно устраняют товарные биржи» [7. С. 222]. Наоборот, роль биржи в современном мире возросла, расширился перечень институциональных инвесторов, а доля банков в совокупных финансовых активах снизилась.

Наряду с процессами концентрации и централизации производства и капитала в ведущих странах наблюдались противоположные процессы. «После второй мировой войны конкуренция не только не уступила место монополии, а возродилась с утроенной энергией. Жизнеспособность конкуренции во многом объясняется той дифференциацией продукта, которую, как отметил Чемберлин, создают конкурирующие фирмы» [7. С. 13]. Кроме того, многократно выросла сравнительная эффективность малых и средних предприятий, производство крупных фирм 
диверсифицировалось, значительно возросла номенклатура выпускаемой продукции, ускорилось обновление ее ассортимента, стали более доступны рыночная информация и капитал.

Вопреки ожиданиям В.И. Ленина уровень коррупции по сравнению с началом XX века существенно снизился, по крайней мере, в ведущих странах. Подкуп путем предоставления места в совете директоров банков и трестов отставным депутатам, чиновникам и т. п., разумеется, имеет место и сегодня. Но коррупция, кумовство и личные унии более характерны для развивающихся стран, а не тех, о которых писал В.И. Ленин.

Вывоз капитала 100 лет назад объяснялся возникновением огромного избытка капитала в передовых странах. В.И. Ленин писал: «Разумеется, если бы капитализм мог развить земледелие, которое теперь повсюду страшно отстало от промышленности, если бы он мог поднять жизненный уровень масс населения, которое повсюду остаётся, несмотря на головокружительный технический прогресс, полуголодным и нищенским, - тогда об избытке капитала не могло бы быть и речи. И такой “довод” сплошь да рядом выдвигается мелкобуржуазными критиками капитализма. Но тогда капитализм не был бы капитализмом, ибо и неравномерность развития и полуголодный уровень жизни масс есть коренные, неизбежные условия и предпосылки этого способа производства. Пока капитализм остаётся капитализмом, избыток капитала обращается не на повышение уровня жизни масс в данной стране, ибо это было бы понижением прибыли капиталистов, а на повышение прибыли путём вывоза капитала за границу, в отсталые страны» [1. С. 339-340]. При этом В.И. Ленин не задается вопросом о том, что произойдет, когда уровень капиталовооруженности в странах-реципиентах приблизится к уровню стран-доноров, а норма прибыли - снизится.

Современная теория платежного баланса и соответствующие модели наглядно демонстрируют, что международное движение товаров, услуг и капитала тесно взаимосвязаны, и вывоз капитала не может вытеснить экспорт товаров и услуг на сколько-нибудь длительное время. Сельское хозяйство перестало быть «страшно отсталым», а проблема физической нехватки продовольствия в мировом масштабе была решена. И это притом, что население Земли увеличилось за последние 100 лет в пять раз. Несоизмеримо вырос уровень жизни в капиталистических странах. Более 
того, при желании В.И. Ленин мог бы заметить рост уровня и качества жизни в конце XIX века у низших классов общества не только в Европе, но и в России.

В отличие от Дж. Гобсона В.И. Ленин не различал колониальную и империалистическую политики. Это объяснялось тем, что все процессы, включая демографические, он связывал с интересами капитала и не хотел признавать даже частичную правоту сторонников теории Т. Мальтуса. Критика К. Каутского, считавшего, что империализм проводит особую политику территориальной экспансии промышленных стран в аграрные области, и, по мнению В.И. Ленина, не замечавшего роли финансового капитала в формировании этой политики, связана с тем, что классовый подход для него был важнейшим принципом [1. С. 387-391]. Для В.И. Ленина высокое отношение прибавочного труда к необходимому было нормой эксплуатации при капитализме и свидетельством алчности буржуазии. Но после пролетарской революции оно стало показателем эффективности социалистической экономики.

Точно так же считалось, что территориальная экспансия в эпоху империализма проводилась ведущими странами в интересах финансовой олигархии, а в случае СССР определялась борьбой за права угнетенного рабочего класса и всех трудящихся. Репрессии, включая смертную казнь, в буржуазном обществе большевики гневно осуждали, но после революции В.И. Ленин писал, что всякая революция чего-то стоит, если она может защищаться. Н.И. Бухарин даже говорил о том, что «пролетарское принуждение во всех своих формах, начиная от расстрелов и кончая трудовой повинностью, является, как парадоксально это ни звучит, методом выработки коммунистического человечества из человеческого материала капиталистической эпохи» [5. С. 168].

Удивительно, но будучи политиком, В.И. Ленин так мало места в своей работе уделил идеологии империализма. А ведь эту идеологию разделяли далеко не только господствующие классы. В.И. Ленин не мог не заметить, с каким энтузиазмом воспринимали известие о начале войны «широкие народные массы», и как этот энтузиазм переходил в шовинизм. Видимо, он полагал, что в распоряжении лидеров революционного пролетариата в нужное время найдутся нужные инструменты для идеологического перевооружения масс. И цитирование Сесиля Родса (если вы не хотите гражданской войны, вы должны стать империалистами), 
говорит о том, что В.И. Ленин прекрасно понимал возможности манипуляции общественным мнением, не боялся гражданской войны, а главное зло видел в реформизме и пацифизме [1. С. 376].

Во многие советские учебники вошли знаменитые пять основных признаков империализма [1. С. 386]: 1) концентрация производства и капитала, дошедшая до такой высокой ступени развития, что она создала монополии, играющие решающую роль в хозяйственной жизни; 2) слияние банкового капитала с промышленным и создание на этой базе «финансового капитала», финансовой олигархии; 3) вывоз капитала, в отличие от вывоза товаров, приобретает особое значение; 4) образуются международные монополистические союзы капиталистов, делящие мир, и 5) закончен территориальный раздел земли крупнейшими капиталистическими державами.

Главный вывод В.И. Ленина состоял в том, что «империализм есть капитализм на той стадии развития, когда сложилось господство монополий и финансового капитала, приобрёл выдающееся значение вывоз капитала, начался раздел мира международными трестами и закончился раздел всей территории земли крупнейшими капиталистическими странами» [1. С. 387].

\section{Вклад советской науки в теорию империализма}

Как было сказано, из обсуждаемой работы В.И. Ленина выросла целая наука «Политическая экономия современного монополистического капитализма». Попробуем кратко обрисовать основные достижения этой науки. Поскольку, вопреки представлениям В.И. Ленина, революции в мировом масштабе не произошло, то была выдвинута идея о том, что революционный процесс растянут во времени, следовательно, общий кризис капитализма состоит из нескольких этапов или стадий. Советские ученые и солидарные с ними зарубежные марксисты выделяли три этапа. Первые два датируются мировыми войнами, а третий был связан с формированием мировой социалистической системы и мирным соревнованием двух систем. «Мировой социализм бросает вызов капиталу тем, что он осуществляет благородные принципы интернационализма и мобилизует все ресурсы для роста благосостояния народа, создания всех условий для всестороннего развития физических и духовных сил человека. Социализм своей политикой, рассчитанной на мирное сосуществование 
с капитализмом и поддержку всех сил внутри его, которые тяготеют к миру, демократии и социальному прогрессу, начинает оказывать все более существенное влияние на ход классовой борьбы в буржуазных государствах» [2. С. 11]. Мирное сосуществование и соревнование двух систем на деле означали раздел мира на зоны влияния в соответствии с ялтинско-потсдамскими соглашениями и обернулось огромным числом прокси-войн, в которых погибло не меньше людей, чем в обеих мировых войнах.

Важной задачей ученых-марксистов являлось доказательство того, что при всех количественных и качественных изменениях капитализм остается в принципе тем же, что и во времена К. Маркса, а империализм капиталистических стран, в сущности, не поменялся со времен В.И. Ленина. «Совершенно несостоятельны буржуазные и реформистские концепции, декларирующие антиимпериалистическое перерождение современного капитализма вследствие распада колониальной империи. Империализм не есть особая политика, он не сводится к владению колониями» [3. С. 20]. Это нетривиальное утверждение, поскольку Р. Люксембург вслед за В.И. Лениным утверждала, что империализм не может существовать и развиваться без колоний [4. С. 20-21].

Советские ученые внимательно следили как за тенденциями социально-экономического развития капиталистических и развивающихся стран, так и за новациями в сфере государственного управления. Но все эти сведения использовались только для того, чтобы подтвердить правильность выводов, сделанных В.И. Лениным еще в 1916 г. Обвинения в апологетической сущности буржуазной науки полностью относились и к большинству советских авторов, с той лишь разницей, что предметом защиты и оправдания была иная система.

Любое явление или событие, начиная от экономических кризисов и инфляции до внедрения систем экономического прогнозирования, планирования и программирования, национализации предприятий и роста государственного аппарата, рассматривались как очередное свидетельство загнивания капитализма и его неспособности к дальнейшему развитию.

Сформировалась концепция государственно-монополистического капитализма как результата сращивания государства и финансовой олигархии. «С ростом государственно-монополистического капитализма значительно усложняется функция 
государственного управления. В среде финансовой олигархии наблюдается растущая тяга к прямому участию в управлении государством. Плутократия жаждет распоряжаться судьбами миллионов людей, диктовать свою волю другим странам, ощущать близость к военной силе и ядерному оружию» [2. Т. 2. С. 212-213]. Зарубежные исследователи и журналисты предоставляли прекрасный материал для подобных выводов, поскольку располагали качественной статистикой о распределении доходов и богатства, динамике безработицы и бедности, чистых активов компаний, числе банкротств и т. п. Советская же статистика была построена таким образом, что самые острые социальноэкономические проблемы были скрыты.

Академик И.И. Иноземцев писал в заключительном разделе об исторической неизбежности революционного низвержения капитализма: «Стремясь “перехитрить” историю, выносящую капитализму как системе неумолимый приговор, буржуазные философы, социологи, экономисты утверждают, что современный капитализм - это-де вовсе не капитализм в его марксистском понимании, лишенный классовых антагонизмов. Однако, как уже было сказано, - и это подтверждается всем фактическим материалом, приводимым в книге, развитие государственномонополистического капитализма, значительно модифицировав капиталистическое общество, ни в коей мере не изменило его основ» [2. Т. 2. С. 399].

А. Пезенти писал: «Единственное новое явление, которое развилось после выхода ленинской книги, есть государственномонополистический капитализм в разных его формах» [4. С. 137].

Более того, уже в 1987 г. С.М. Меньшиков в диалоге с Дж. К. Гелбрейтом отстаивал все те же тезисы, хотя последнюю стадию переживала совсем другая система [8].

Структура многочисленных работ по теории государственно-монополистического капитализма, их содержание, логика, аргументация и выводы очень близки, если не совпадают с теми, которые были предложены В.И. Лениным. Сами же эти работы, несмотря на множество новых данных и аргументов, являются лишь расширенными комментариями к «Империализму, как высшей стадии капитализма».

Было бы ошибкой укорять советских ученых в некомпетентности и непрофессионализме. Они достаточно хорошо 
анализировали и понимали процессы, происходившие в странах с рыночной экономикой. Но если они хотели заниматься теорией, то их исследование сводилось к разрешению противоречия между стоимостью, ценой производства и монопольными ценами, а также доказательству того, что отклонения между ними не противоречат закону стоимости и являются его прямым следствием, ведут к росту антагонизма между трудом и капиталом и углублению противоречий капитализма [9].

\section{Заключение}

Нельзя пренебрежительно относиться к тем схемам, формулам и цитатам, которые были заложены в нас в школе или университете. Как бы ни широка была пропасть между моделями и стереотипами, заложенными в процессе обучения, и последующим опытом и знаниями, усвоенными в зрелом возрасте, избавиться от привычного мировосприятия и двигаться дальше удается очень немногим, поскольку новые процессы и явления мы рассматриваем через призму ранее усвоенных «истин».

В СССР осуждались догматизм и начетничество и раздавались призывы к творческому развитию марксизма-ленинизма. Но обязательное цитирование классиков, равно как и решений партийных съездов было важнейшим аргументом при отстаивании истинности теоретических концепций и практических выводов. Трудно добиться прогресса в науке, если невозможно подвергать сомнению и критиковать предшественников, даже ставших классиками.

Поскольку истинным считалось, что империализм есть высшая и последняя стадия капитализма, подготавливающая максимальную степень обобществления производства, все инструменты управления в условиях диктатуры пролетариата, то после революции следовало завершить процессы монополизации производства и распределения. А именно: национализировать и слить банки и создать на этой основе единую бухгалтерию, ликвидировать биржи, на месте множества предприятий создать синдикаты и тресты и т. п. В результате была построена монополистическая экономика государственного капитализма, которая, в соответствии с ленинским анализом, на определенном этапе проявила тенденцию к загниванию и паразитизму.

Анализируя в 1996 г. проблемы переходного периода в России, Ю.Я. Ольсевич приходит к выводу, что выбор чрезвычайно 
рискованного и разорительного варианта перехода от централизованной к рыночной системе был связан с тем, что «в СССР сложились мощные силы, заинтересованные в сохранении монопольного положения предприятий и их объединений и незаинтересованные в рыночной конкуренции» [7. С. 24].

Институты постсоветской экономики формировали отнюдь не широкие народные массы или ученые. Эта миссия выпала на долю советских, партийных и комсомольских функционеров, бюрократов, представителей силовых структур и теневого бизнеса.

Когда они достигли консенсуса в том, что эксперимент с реальным социализмом нужно закончить и перейти к строительству капитализма, то решили, что не следует восстанавливать «старый» капитализм свободной конкуренции, а надо перейти сразу к строительству его высшей фазы: к государственно-монополистическому капитализму. В СССР монополии уже были созданы, оставалось их только приватизировать, даже если они формально оставались в собственности государства. В кратчайшие сроки в стране появились тысячи банков и сотни бирж, оперировавшие с фиктивным капиталом, быстро сформировались финансовый капитал и финансовая олигархия, огромных масштабов достиг вывоз капитала, сыгравший не меньшую роль в развитии станы, чем вывоз товаров, финансово-промышленные группы приобрели транснациональный характер и включились в международную конкуренцию. Осталось только начать борьбу за передел мира, используя межимпериалистические противоречия.

Что касается «империалистических» стран, то за последние 100 лет они постепенно отказались от подобной политики, прилагают значительные усилия к демонополизации экономики и развитию конкуренции, жестко регулируют деятельность финансовых институтов, ограничивают слияние банковского и промышленного капитала, поддерживают малый бизнес, провели деколонизацию и пытаются контролировать трансграничные финансовые потоки. Много сделано для демилитаризации экономики. Нельзя сказать, что все указанные мероприятия завершились успехом, но общий вектор перемен вполне очевиден. Возможно, множество работ типа «Империализма» В.И. Ленина и «Финансового капитала» Р. Гильфердинга сыграли роль анти-утопии для правительств и общественности ряда стран, но, скорее всего, еще сильнее повлияли драматические события $\mathrm{XX}$ века. 
К произведениям В.И. Ленина, включая «Империализм», целиком относится характеристика, данная В. Парето «Капиталу» Карла Маркса. Парето заявлял, что марксизм ввел в заблуждение неграмотные массы благодаря той страстности, которая для него характерна, а грамотных людей привлек своей кажущейся логической стройностью. Лишь страстность, присущая Марксу, сделала его учение столь привлекательным, а материалистический взгляд на историю имеет черты подлинно научной теории, хотя и является лишь рассчитанным на эмоции придатком к социалистической теории [10. С. 251].

В чем В.И. Ленин оказался абсолютно прав, так это в том, что монополии в экономике и политике тесно взаимосвязаны, неизбежно ведут к формированию финансовой олигархии, конфликтам и войнам с другими государствами, обнищанию народных масс.

\section{Литература}

1. Ленин В. И. Империализм, как высшая стадия капитализма (популярный очерк) ПСС, изд. 5. Т. 27. - М.: Государственное издательство политической литературы, 1962. - 643 с. Полный вариант представлен в сети Интернет URL: http://www.esperanto.mv.ru/Marksismo/Lenin_ Imperialism/imp.html

2. Политическая экономия современного монополистического капитализма. В 2-х томах / Отв. Ред. Н. Н. Иноземцев и др. - М.: Мысль, 1971. T. $1 .-455$ с., T. 2. -413 c.

3. Меньшиков С. М. Современный капитализм. Краткая политэкономия. - М.: Мысль, 1974. - 262 с.

4. Пезенти А. Очерки политической экономии капитализма В 2-х т. / Под ред. А. Г. Милейковского и др. - М.: Прогресс, 1976. Т. 2. - 885 с.

5. Бухарин Н. И. Проблемы теории и практики социализма. - М.: Политиздат, 1989. - 512 с.

6. Чемберлин Э. Теория монополистической конкуренции: (Реориентация теории стоимости) / Под ред. Ю. Я. Ольсевича. - М.: Экономика, 1996. - 351 с.

7. Гильфердинг Р. Финансовый капитал. Исследование новейшей фазы в развитии капитализма. - М.: Изд-во социально-экономической литературы, 1959. - 491 с.

8. Гелбрейт Дж. К., Меньшиков С. Капитализм, социализм, сосуществование. - М.: Прогресс, 1988. - 200 с.

9. Аганбегян А. Г. Вопросы теории монополистической цены на примере США. - М.: Изд-во МГУ, 1961. - 144 с.

10. Селигмен Б. Основные течения современной экономической мысли. - М.: Прогресс, 1968. - 600 с. 